\title{
PROJETO LICURI: UMA PROPOSTA DE REAPLICAÇÃO DA TECNOLOGIA SOCIAL
}

\section{LICURI PROJECT: A PROPOSED REAPPLICATION OF SOCIAL TECHNOLOGY}

\author{
PROYECTO LICURI: UNA PROPUESTA DE \\ REAPLICACIÓN DE LA TECNOLOGÍA SOCIAL
}

\author{
Camila de Mattos Lima Andrade ${ }^{1}$ \\ Djane Santiago de Jesus ${ }^{2}$ \\ Carla Renata Santos dos Santos ${ }^{3}$
}

\begin{abstract}
RESUMO: O presente estudo aborda aspectos conceituais, históricos, teórico-práticos, numa perspectiva crítica, acerca das Tecnologias Sociais (TS) e tem como seu principal escopo retratar uma proposta de reaplicação de tecnologias sociais desenvolvidas no âmbito do Projeto Licuri IFBA, a partir das experiências vivenciadas em projeto de extensão na região de Serra Pelada-Monte Branco, comunidade de Barraquinha, zona rural do município de Jequié-Bahia. Por meio do levantamento de referencial teórico e relatos de experiência, foram planejadas e executadas fases preparatórias para possível reaplicação dessas TS, cujo processo de desenvolvimento e reaplicação tecnológica está fundado nos conceitos de TS preconizados principalmente por Dagnino (2004), Dias e Novaes (2010); Incubação Social por Santos, Jesus e Cypriano (2017). Como produto das ações desenvolvidas, foi possível a criação de um plano de metas e ações visando à criação de novos produtos com o uso do licuri como componente, preocupação com a adequação às práticas de higiene e segurança alimentar, aplicação de algumas técnicas de empreendedorismo aos produtos desenvolvidos. Portanto, o estudo poderá colaborar com pesquisas na área de TS, assim como projetos que visem à reaplicação de TS em outras regiões.
\end{abstract}

PALAVRAS-CHAVE: Tecnologias Sociais. Reaplicação de TS. Projeto Licuri.

Licença CC BY:

Artigo distribuído sob os termos Creative

Commons, permite uso e distribuição irrestrita em qualquer meio desde que o autor credite a fonte original.
ABSTRACT:This study addresses, from a critical perspective, conceptual, historical, theoretical and practical aspects of Social Technologies (ST). Its main scope is to outline a proposal for the reapplication of social technologies developed within the Licuri IFBA Project, based on experiences of extension project in the region of Serra PeladaMonte Branco, Barraquinha community, in the rural zone of the municipality of JequiéBahia. Through the theoretical reference survey and reports of experience, preparatory phases were planned and executed for the possible reapplication of these ST, whose process of development and technological reapplication is based on the concepts of ST

1 Mestrado Profissional em Propriedade Intelectual e Transferência de Tecnologia para Inovação Instituto Federal de Educação, Ciência e Tecnologia da Bahia: camilamla@, ifba.edu.br. djane@ifba.edu.br. carlarenata@ifba.edu.br. 
recommended mainly by Dagnino (2004), Dias and Novaes (2010); Social Incubation by Santos, Jesus and Cypriano (2017). Through the actions developed, it was possible to create a plan of goals and actions aimed at the creation of new products using Licuri as a component, a concern with adaptation to hygiene and food safety practices, application of some entrepreneurship techniques for the products developed. This study may, therefore, collaborate with research in the area of ST, as well as projects aimed at reapplying ST in other regions.

KEYWORDS: Social Technologies. TS reapplication. Licuri Project.

RESUMEN: El presente estudio aborda aspectos conceptuales, históricos, teórico-prácticos, en una perspectiva crítica, acerca de las Tecnologías Sociales (TS) y tiene como su principal objetivo retratar una propuesta de reaplicación de tecnologías sociales desarrolladas en el ámbito del Proyecto Licuri IFBA, a partir de las experiencias vividas en proyecto de extensión en la región de Sierra Pelada-Monte Branco, comunidad de Barraquinha, zona rural del municipio de Jequié-Bahia. Por medio del análisis en el referencial teórico y relatos de experiencias, fueron planeados y ejecutados fases preliminares para posible reaplicación de estas TS, cuyo proceso de desarrollo y reaplicación tecnológica está fundada en los conceptos de TS preconizados principalmente por Dagnino (2004), Dias y Novaes (2010); Incubación Social por Santos, Jesus y Cypriano (2017). Como producto de las acciones desarrolladas, fue posible la creación de un plan de metas y acciones visando a la creación de nuevos productos con el uso de licuri como componente, preocupación con la adecuación a las prácticas de higiene y seguridad alimentar, aplicación de algunas técnicas de empreendedorismo a los productos desarrollados. Por lo tanto, el estudio podrá colaborar con investigaciones en el área de TS, así como proyectos que visen a la reaplicación de TS en otras regiones.

PALABRAS-CLAVE: Tecnologías Sociales. Reaplicación de TS. Proyecto Licuri.

\section{INTRODUÇÃO}

A Tecnologia Social (TS) é um termo cunhado para designar todo e qualquer conhecimento pensado e construído coletivamente, com o objetivo de resolver uma demanda social, a partir de uma reunião de saberes, tanto científicos, como populares. O termo se consolidou no Brasil, motivado por discussões acerca de 'tecnologia apropriada', retomadas a partir do ano 2000.

No entanto, como se constitui o marco analítico-conceitual das Tecnologias Sociais e quais as implicações contidas neste conceito? E, para mais além, como é possível reaplicar Tecnologias Sociais em ambientes com peculiaridades e distinções tão marcantes?

O presente estudo se consubstancia numa proposta de Reaplicação de Tecnologias Sociais elaboradas a partir de ações extensionistas desenvolvidas, desde o ano de 2018, na região inserida no Território Médio Rio das Contas, semiárido baiano, em uma comunidade rural conhecida popularmente como Barraquinha, localizada na região de Serra Pelada, distrito de Monte Branco, zona rural do município de Jequié-BA e organizadas em uma Associação dos Pequenos Agricultores e Pecuaristas de Serra Pelada e Barraquinha. Durante a execução do referido projeto de extensão, os comunitários efetuaram matrícula nas oficinas e assinaram termo de Consentimento Livre e Esclarecido e Termo de Autorização e Divulgação de informações e imagens. As ações objetivaram uma possível reaplicação, nesta região, de Tecnologia(s) Social(is) desenvolvidas no Projeto Licuri, devido à predominância deste fruto (o licuri) no local, como também com vistas a corroborar no enfrentamento das dificuldades vivenciadas pela citada comunidade rural. 
O Projeto Licuri, do Instituto Federal de Educação, Ciência e Tecnologia da Bahia (IFBA), há mais de uma década, conta com profissionais que desenvolvem pesquisa e extensão relacionadas ao licuri na região de Caldeirão Grande-BA, em parceria com agricultores familiares que compõem a Cooperativa de Colhedores e Beneficiadores de Licuri (Cooperlic), influenciando positivamente na realidade socioeconômica local.

Sendo assim, tomou-se como ponto de partida para o estudo os questionamentos iniciais acerca das Tecnologias Sociais, a fim de evidenciar algumas bases acerca do marco analítico-conceitual das mesmas, bem como os aspectos importantes que caracterizam a discussão, o desenvolvimento, a implantação e a (re)aplicação dessas tecnologias. Na sequência, são apresentados os aspectos gerais, as potencialidades e as possibilidades no que diz respeito às Tecnologias Sociais desenvolvidas no âmbito do Projeto Licuri do Instituto Federal de Educação, Ciência e Tecnologia da Bahia (IFBA). Neste contexto, com base nestas experiências, é formulada uma proposta de reaplicação de Tecnologia(s) Social(is) para a citada comunidade de Barraquinha.

Posto isso, a composição deste estudo poderá contribuir com estudiosos e comunidades que desejam trilhar os caminhos que conduzem à reaplicação de Tecnologias Sociais, desde a sua conceituação, diagnóstico, etapas propostas, assim como os fatores e os agentes que participam e influenciam neste processo.

A produção científica, de caráter descritivo e analítico, corrobora na consolidação das bases analítico-conceituais e diretrizes para reaplicação de Tecnologias Sociais, por meio da realização de um estudo, que relacionou a experiência vivenciada pelo Projeto Licuri em Caldeirão Grande/BA à ação extensionista desenvolvida em Serra Pelada-Monte Branco-Jequié-BA, comunidade rural de Barraquinha. Portanto, caracteriza-se como uma pesquisa de natureza aplicada, cujo método de abordagem qualitativo se deu pelo enfoque subjetivo, a fim de compreender os comportamentos, as experiências compartilhadas do grupo-alvo eleito, qual seja, o comunitário de Barraquinha e Serra Pelada. Assim, as etapas se desenvolveram pelo levantamento de referencial teórico, análise dos resultados obtidos no Projeto Licuri e por meio das vivências no projeto de extensão intitulado Oficinas de Qualificação para o Beneficiamento do Licuri, no IFBA Campus Jequié.

\section{AS TECNOLOGIAS SOCIAIS - MARCO ANALÍTICO CONCEITUAL E PERSPECTIVA CRÍTICA}

No Brasil, a criação da Petrobras, em 1953, fomentou ações de responsabilidade social, ambiental, cultural e esportiva, com vistas à melhoria da qualidade de vida das populações localizadas em sua área de atuação. Não há que se considerar este como o marco das TS no Brasil, porém o fomento a ações que visem ao desenvolvimento social se coadunam e influenciaram de forma positiva o desenvolvimento das TS que vieram a se consolidar 50 anos depois.

Wilson Santarosa, Gerente Executivo de Comunicação Institucional da Petrobras, em 2004, no prefácio da obra financiada por esta empresa, intitulada "Tecnologia social: uma estratégia para o desenvolvimento”, destaca que tais iniciativas ganharam maior escala em 2003, com a implantação dos programas Petrobras Fome Zero, voltados para ações sociais, o Programa Petrobras Cultural e o Programa Petrobras Ambiental, atingindo mais de mil projetos patrocinados (LASSANCE JR. et al., 2004).

Neste contexto, surgem, no país, as primeiras iniciativas de desenvolvimento e reaplicação 
de Tecnologias Sociais da Petrobras, que representaram um marco para as metodologias de inclusão social, construídas em interação com as comunidades e por elas apropriadas. Mais tarde, com o surgimento da Rede de Tecnologias Sociais (RTS), em 2005, seriam chamadas de Tecnologias Sociais.

Ainda segundo Lassance Jr. et al (2004), como forma de viabilizar a reaplicação das TS, a Fundação Banco do Brasil corroborou neste processo, construindo um modelo de franquia social que atuou na transferência do conhecimento social para outras instituições, entidades e empresas, inserindo as etapas necessárias de reaplicação e atuou com enfoque na educação e na geração de renda, com vistas à reaplicação de TS, por meio da mobilização comunitária e da articulação de parcerias.

Em paralelo às ações desempenhadas pela Petrobras e Fundação Banco do Brasil, a publicação do caderno de textos para discussão intitulada Tecnologia para a Inclusão Social e Políticas Públicas na América Latina, organizada por Renato Dagnino, fez um resgate ao movimento mundial que antecedeu à consolidação do conceito de Tecnologia Social, o da Tecnologia Apropriada (TA), que tem como seu principal expoente Mahatma Gandhi.

Rodrigues e Barbieri (2008) destacam que, entre as décadas de 60 e 70, Gandhi, percebendo o incentivo às TA como elemento de transformação social em relação à situação econômicoexploratória vivenciada pela Índia no início do século passado, imprime esforços para popularizar a roca de fiar ${ }^{5}$ manual, que se torna o primeiro equipamento tecnologicamente apropriado. O movimento foi caracterizado como uma reação aos padrões de crescimento econômico do pós-guerra.

Dagnino, Brandão e Novaes (2004), ao analisarem a Tecnologia Apropriada, apontam que as diversas correntes desta teoria mencionam um produto, e não um processo. Ademais, identificam que este como o principal obstáculo para o movimento das TAs não terem colocado em prática as suas ideias: o fato não ter explicitado a organização acerca do processo. Consideram, pois, que a inovação não deve ser pensada e executada em um lugar e aplicada em outro, e sim como um processo desenvolvido no ambiente onde essa tecnologia deva ser utilizada, como também com a participação direta dos atores que irão utilizá-la. As bases conceituais e constitutivas de Tecnologia Social vêm sendo aprimoradas ao longo do tempo. Mello e Mello (2010) destacam que o debate acerca do desenvolvimento e do papel da tecnologia no combate à exclusão desencadearam uma série de questionamentos de ordem teórica e prática, que se passará a evidenciar neste capítulo.

A reflexão é pertinente, pois que, como ressalta Dagnino et al. (2010), as maneiras distintas como os grupos sociais interpretam e utilizam um objeto técnico não lhe são extrínsecas, dizem respeito a um conhecimento tradicional adquirido. Esta interação entre os grupos e seus objetos técnicos produzem, ao longo de um processo de construção sociotécnica, mudanças na própria natureza dos objetos. Por essa razão, só é possível entender o desenvolvimento de um artefato tecnológico a partir do estudo do contexto sociopolítico e a relação de forças entre os diversos grupos com ele envolvidos. Assim, as Tecnologias Sociais concebidas a partir de uma proposta crítica têm como elementos diferenciais a emancipação do indivíduo, o processo de construção social, a valorização

4 Rodrigues e Barbieri (2008) destacam o conceito de TA de Willoughby (1990), que define em termos gerais como uma tecnologia que deve se ajustar ou se adaptar a algum propósito ou uso específico, utilizando o termo 'apropriada'. Mas há o questionamento acerca do que se apropria, o que leva à necessidade de examinar a apropriabilidade da tecnologia para cada situação específica e menciona a falta de critérios específicos com que a expressão tecnologia apropriada foi sendo utilizada de modo indiscriminado.

5 Roca de fiar é o nome dado à máquina que permite filar (reduzir uma fibra a fio). O dispositivo dispõe de uma vara que finaliza num cabeçal onde a fibra se enrola; uma roda, uma manivela ou um pedal e um suporte que gira para realizar o filamento. 
da aprendizagem, o respeito à cultura local, as demandas sociais como origem e propósito, a apropriação da tecnologia, a sustentabilidade, a democratização do conhecimento, a transformação social e a multiplicidade de soluções (FREITAS; SEGATTO, 2014).

Observa-se, então, que os primeiros autores citados traçam diretrizes de ordem mais empírica, enquanto os demais consolidam o marco analítico-conceitual acerca das TS, assegurando-lhe uma identidade na seara das estratégias de transformação e inclusão social.

\section{O PROJETO LICURI E SUA POTENCIALIZAÇÃO NAS TECNOLOGIAS SOCIAIS: POSSIBILID̉ADE DE REAPLICAÇÃO}

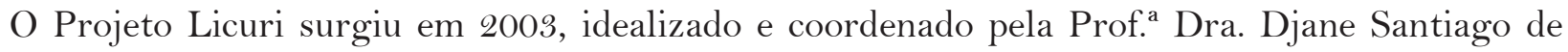
Jesus, servidora do Instituto Federal de Educação, Ciência e Tecnologia da Bahia (IFBA), Campus Salvador. Neste projeto, um grupo de profissionais mostrou-se disposto a desenvolver ações associando os pilares da educação - ensino e pesquisa acerca do licuri, numa ação de extensão universitária. Os resultados das pesquisas realizadas, em 2005, foram aplicados no município de Caldeirão Grande-Bahia, buscando resgatar a cultura extrativista, fortalecer a cadeia produtiva do licuri na região, por meio da construção de Tecnologias Sociais e possibilitar o aumento da renda, a fixação do homem no campo, a redução das desigualdades. ${ }^{6}$

Conforme destacam Carvalho, Ferreira e Alves (2014), o licuri (Syagrus coronata) é uma palmeira nativa do Semiárido Nordestino (Bahia, Alagoas, Sergipe e Pernambuco) e do norte do estado de Minas Gerais, sendo predominante no semiárido baiano, sobretudo nos municípios de Capim Grosso, Serrolândia, Quixabeira, São José do Jacuípe, Várzea da Roça, Mairi, Jacobina, Várzea do Poço, Senhor do Bonfim, Campo Formoso e Caldeirão Grande. Desta forma, é possível afirmar a relevância do licuri para o semiárido baiano.

O IFBA é uma instituição de ensino, criada mediante transformação do Centro Federal de Educação Tecnológica da Bahia (antigo CEFET/BA), por meio da Lei Federal 11.892. O instituto oferece, numa única organização institucional, educação tecnológica profissional em todos os níveis, possui uma estrutura multicampi, com unidades de ensino em diversas regiões estratégicas do estado, tendo como uma de suas missões "a promoção da cidadania, oferecendo ensino, pesquisa e extensão com qualidade socialmente referenciada, objetivando o desenvolvimento sustentável do país $\square .{ }^{7}$

O Projeto Licuri, em concordância com a missão do IFBA, apoia-se na valorização da inovação voltada para a inclusão social e para o desenvolvimento sustentável do semiárido baiano, objetivando que comunidades de agricultores(as), incluindo as de remanescentes quilombolas, atuem e permaneçam no mercado de trabalho e qualificação profissional dos seus membros, potencializando a organização solidária para compra de insumos e vendas de produtos ${ }^{8}$.

O processo de interação entre o IFBA e a comunidade de Caldeirão Grande se deu por meio de ações de pesquisa e extensão desenvolvidas na região por pesquisadores do Projeto Licuri e foi intensificado a partir da incubação social. Este processo de incubação consiste na disponibilização de assessoria técnica a empreendimentos advindos de projetos sociais. Tais projetos sociais, por sua vez, podem se constituir em seu bojo, como relevante ferramenta de desenvolvimento social, à

$6 \quad$ Fonte: https://portal.ifba.edu.br/proex/acoes/projeto-licuri.

7 Fonte: https://portal.ifba.edu.br/seabra/institucional/IFBA )

8 Fonte: https://portal.ifba.edu.br/proex/acoes/projeto-licuri ) 
(re)aplicação de Tecnologias Sociais.

Neste ínterim, as ICTs, tais como o IFBA, prestam a referida assistência técnica a comunidades ou organizações que desenvolvem projetos sociais, por meio do processo de incubação, que deram origem a incubadoras sociais. Estas incubadoras proporcionam o surgimento de um ambiente empreendedor que beneficia a sociedade, principalmente na melhoria significativa da qualidade de vida, visão de mundo mais abrangente e cidadania dos seus habitantes.

Santos, Jesus e Cypriano (2017b) ressaltam o aspecto do esforço multidisciplinar que envolve o processo de incubação, considerando, nesta demanda, a atuação de distintos campos disciplinares, incidindo na produção e na aplicação coletiva dos agentes da academia e dos(as) agricultores(as)/ cooperados(as), a fim de consolidar o conhecimento necessário à promoção da autossustentabilidade da cooperativa. Esta, por sua vez, é compreendida não só como empreendimento econômico, mas também como organização social e política. Logo, destacam o aspecto político e educativo da incubação, bem como os três eixos que fundamentam o processo:

Nessa perspectiva, a incubação foi concebida como um processo educativo, como também um processo político, que buscou a promoção da autonomia dos atores do empreendimento. Este processo é fundamentado em três eixos: o políticoideológico - que busca desvendar as razões e sentidos que provocam a inserção social subalterna e dependente de parcelas da população trabalhadora, produzindo uma conscientização crítica dos participantes quanto ao seu papel no mundo; o sócio-organizacional - que visa à organização sócio-produtiva para o trabalho associado em bases autogestionárias (dimensão que se revela a mais desafiadora da incubação em razão da cultura individualista, competitiva e heterogestionária profundamente arraigada em todos os extratos sociais da população); e o técnicoprodutivo - organizado a partir de uma adequação sociotécnica com vistas ao desenvolvimento e operacionalização de tecnologias sociais. (SANTOS; JESUS; CYPRIANO, 2017b, p. 754).

No intuito de consolidar os aspectos sociais e solidários nos processos de incubação, destaca-se a importante atuação das Incubadoras Tecnológicas de Cooperativas Populares (ITCPs) a partir de 1995. Matarazzo e Boeira (2016) salientam que, no decorrer dos anos, as ITCPs se expandiram e se tornaram uma rede, fundamentalmente composta por atores vinculados às universidades públicas e comunitárias. Os autores ainda destacam que "as ITCPs podem ser consideradas um tipo de Tecnologia Social, ou seja, arranjos organizacionais voltados para a busca de soluções de problemas de segmentos vulneráveis da sociedade, especialmente em termos sociais e econômicos, mas também em termos ambientais, só que em menor proporção” (MATARAZZO; BOEIRA, 2016, p. 208).

Santos, Jesus e Cypriano (2017a), por sua vez, detalham o processo de incubação ocorrido no contexto da cooperativa comunitária integrada ao Projeto Licuri. A incubação da Cooperativa de Colhedores e Beneficiadores de Licuri Caldeirão Grande Bahia (Cooperlic), por meio da ITCP/IFBA, oferece pressupostos prático-teóricos importantes na concepção e na realização das atividades de incubação relacionadas às TS. Os autores destacam que a incubação incide na produção e na aplicação coletiva do conhecimento necessário à autossustentabilidade da cooperativa, por parte de todos os atores envolvidos, os da academia e os agricultores/ cooperados. Não se trata apenas de um empreendimento econômico, e sim uma organização social e política (SANTOS; JESUS; CYPRIANO; $2017 \mathrm{a})$. 
O processo de coconstrução de Tecnologias Sociais, verificado na comunidade Caldeirão GrandeBA, é, portanto, uma parceria entre a Cooperlic e o IFBA, por meio do Projeto Licuri. O citado projeto desenvolveu, ao longo de mais de uma década de pesquisas, Tecnologias Sociais que podem ser selecionadas, algumas delas para serem reaplicadas em outras comunidades, mediante etapas de adequação sociotécnica necessária, a partir de processo participativo realizado entre os pesquisadores extensionistas envolvidos e a comunidade escolhida.

No Projeto Licuri do IFBA, os primeiros relatos, entrevistas veiculadas na mídia, demonstravam que, quando os pesquisadores chegaram à região de Caldeirão Grande-BA, os moradores tinham o hábito de "catar" o licuri que caía no chão das propriedades rurais, ou era ruminado pelo gado e, posteriormente, quebrar o licuri com a pedra. Santos, Jesus e Cypriano (2017a) revelam que, durante o processo de qualificação, pesquisadores e comunidade traçaram uma nova estratégia de colheita do fruto ainda no pé, que diminuía os riscos de picadas de animais peçonhentos e elevavam a qualidade dos produtos derivados que eram feitos a partir do licuri, inclusive para a alimentação. Para isso, foram necessárias, entre outras ações, aprofundar o conhecimento sobre o fruto, definir as épocas de colheita, identificar aspectos físicos que sinalizariam o momento adequado para realizar a colheita diretamente no pé, antes que o fruto caísse ao chão, reduzindo, inclusive, o índice de infestação animal, o chamado morotó, comum de ser encontrado no licuri catado no chão.

Pode-se considerar esta importante mudança (aperfeiçoamento) no método de colheita, que deu origem ao "Programa Colhedor de Licuri”, idealizado pelos pesquisadores e pelos moradores da comunidade, como uma Tecnologia Social relevante, visto que, para ser desenvolvida e executada com êxito, necessitou da participação de todos os atores envolvidos e, de fato, contribuiu na melhoria de vida da comunidade.

O trabalho desenvolvido por meio da parceria entre o IFBA e a Cooperlic ganha destaque devido à sua abrangência que, em 2016, já atingia mais de mil beneficiados. Conforme informações adquiridas no site do IFBA Projeto Licuri, no ano de 2009, o projeto atendeu 1938 famílias agroextrativistas, sendo 1067 homens e 871 mulheres, com faixa etária de 1087 abaixo de 18 anos e 93 acima de 60 anos no município de Caldeirão Grande ${ }^{9}$.

Como resultado mais significativo no projeto, destacam-se as ações que vêm despertando a comunidade do semiárido baiano para a relevância do fortalecimento das cadeias produtivas dos frutos típicos da região, por meio da construção de Tecnologias Sociais, associadas à geração de trabalho e renda, conhecimento, bem-estar e cidadania para as comunidades regionais. Tais ações desenvolvidas pelo projeto culminaram na vitória, em primeiro lugar, no Prêmio de Inovação FINEP 2010 ${ }^{10}$, Categoria Tecnologias Sociais, Regional Nordeste. Jesus et al. (2011) afirmam que este resultado pode ser verificado a partir da visualização da relação produção/área territorial, que alcançou $1,3 \mathrm{t} / \mathrm{km}^{2}$, enquanto a relação produção/habitante chega a $50,6 \mathrm{~kg} / \mathrm{hab}$., até 10 vezes superior às dos outros municípios, com base na produção do ano de 2010.

Observa-se que, além de promover desenvolvimento econômico, o Projeto Licuri trouxe impactos socioculturais importantes. Segundo Carvalho e Ferreira (2016), em 12 de julho de 2015, a Comunidade de São Miguel no Município de Caldeirão Grande sediou a mais recente versão da $8^{\text {a }}$ Festa do Licuri, onde foi ampliada a discussão da Lei do Licuri do âmbito municipal para o estadual

9 Informações extraídas do site do Projeto Licuri IFBA (https:/ / portal.ifba.edu.br/proex/acoes / projeto-licuri ).

10 O Prêmio é um reconhecimento a quem faz inovação no país. Além de troféus, os vencedores receberam recursos do programa de Subvenção Econômica, que variaram de $\mathrm{R} \$ 120$ mil a $\mathrm{R} \$ 2$ milhões, dependendo da categoria premiada. A verba foi para ser aplicada no desenvolvimento dos projetos. 
Durante o desenvolvimento da pesquisa, em contato com as pesquisadoras ligadas ao Projeto Licuri, verificou-se que foram desenvolvidas outras diversas Tecnologias Sociais, como a máquina de quebra do licuri, secador solar, despolpadeira, uma ampla cadeia produtiva que envolve artesanato, alimentos, cosméticos, e tem no óleo de licuri um dos seus principais produtos. Observam-se nos insumos e nos produtos características inovadoras e traços de identidade da comunidade.

\section{CONSTRUÇÃO DE UMA PROPOSTA DE REAPLICAÇÃO DE TECNOLOGIAS SOCIAIS}

O caráter integrador da proposta se percebe na medida em que o locus da ação é uma comunidade rural que vive basicamente da renda advinda de agricultura familiar, com pouca infraestrutura para o cultivo e produção. O desenvolvimento da proposta foi construído com a base na realização de visitas técnicas e oficinas voltadas ao beneficiamento do licuri (projeto de extensão) as quais, prioritariamente, pretenderam conhecer a comunidade estudada, seus anseios, dificuldades enfrentadas, por meio da realização de um diagnóstico participativo. Em contrapartida, propôs-se fornecer informações qualificadas, de forma educativa, aos comunitários, como também a elaboração de uma proposta de possível (re)aplicação de tecnologia(s) social(is) para o fortalecimento da cultura do licuri e, por conseguinte, um incremento na renda familiar da comunidade.

As citadas visitas e oficinas foram ações representativas da intenção de promover, na comunidade estudada, as condições necessárias - adequação sociotécnica - para reaplicação de Tecnologias Sociais desenvolvidas pelo Projeto Licuri do IFBA, mediante as suas necessidades, manifestação de vontade - diagnóstico participativo - e iniciativa. Outrossim, a pesquisa viabilizou a identificação das TS com maiores potenciais de reaplicação a partir do diagnóstico participativo realizado e da articulação dos demais fatores e atores implicados no processo, porém não determina qual(is) delas será(serão) reaplicada(s), visto que a adequação demanda tempo para o transcurso das fases, o percurso pelos eixos e circuitos evidenciados nos estudos acerca das TS.

Em suma, para a execução dos procedimentos metodológicos e operacionais de pesquisa, foram implementadas as seguintes etapas e instrumentos técnico-operacionais demonstrados no Quadro 1. Este quadro foi baseado nas técnicas e nos instrumentais técnicos e teórico-práticos elaborados por Chaves et al.(2012). 
Quadro 1 - Etapas e Instrumentos Metodológicos da Pesquisa

\begin{tabular}{|c|c|c|c|}
\hline Etapas & Período & Técnica & $\begin{array}{l}\text { Instrumentos } \\
\text { Técnico- } \\
\text { Operacionais }\end{array}$ \\
\hline Visitas técnicas exploratórias & $\begin{array}{l}\text { 14/09/2017, } \\
01 / 10 / 2017\end{array}$ & $\begin{array}{l}\text { Conversas Semi- } \\
\text { informais }\end{array}$ & $\begin{array}{c}\text { - Visitas Domiciliares; } \\
\text { - Diálogos Pertinentes } \\
\text { entre os envolvidos no } \\
\text { projeto. } \\
\text { - Registro } \\
\text { Fonográfico }\end{array}$ \\
\hline $\begin{array}{c}\text { Planejamento, estruturação } \\
\text { e submissão do projeto de } \\
\text { extensão }\end{array}$ & $\begin{array}{c}\text { Junho a outubro/2018 } \\
\text { - Projeto submetido a Edital no } \\
\text { 01/2018 em 10/07/2018 } \\
\text { - Projeto Submetido a Edital no } \\
\text { 02/2018 em 23/10/2018 }\end{array}$ & $\begin{array}{c}\text { Elaboração } \\
\text { de Projeto de } \\
\text { Extensão }\end{array}$ & $\begin{array}{l}\text { - Registro no } \\
\text { Sistema Unificado de } \\
\text { Administração Pública } \\
\text { (SUAP) }\end{array}$ \\
\hline $\begin{array}{c}\text { Realização de Oficinas: } \\
\text { - Diagnóstico Participativo } \\
\text { - Empreendedorismo Rural } \\
\text { - Adequação do Espaço físico } \\
\text { e Infraestrutura de Produção } \\
\text { - Gestão de Recursos Hídricos } \\
\text { e Condições de Higiene e } \\
\text { Segurança para o Preparo } \\
\text { Alimentar }\end{array}$ & $\begin{array}{l}\text { 09/10/2018; } \\
31 / 10 / 2018 \\
07 / 11 / 2018 \\
14 / 11 / 2018\end{array}$ & $\begin{array}{c}\text { - Conversas Semi- } \\
\text { informais } \\
\text { - Observação } \\
\text { Participante, } \\
\text { Sistemática e } \\
\text { Assistemática }\end{array}$ & $\begin{array}{c}\text { - Formulário } \\
\text { “Conhecendo os } \\
\text { agricultores de Jequié/ } \\
\text { Bahia” } \\
\text { - Reuniões com } \\
\text { dinâmicas de grupo: } \\
\text { Sociometria e } \\
\text { Memória Coletiva } \\
\text { - Acompanhamento de } \\
\text { atividades produtivas, } \\
\text { organizativas e } \\
\text { culturais; } \\
\text { - Registro Fotográfico } \\
\text { das oficinas que } \\
\text { ocorrem durante o } \\
\text { desenvolvimento da } \\
\text { pesquisa. }\end{array}$ \\
\hline $\begin{array}{c}\text { Elaboração de projetos para } \\
\text { captação de recursos }\end{array}$ & $\begin{array}{l}\text { Janeiro a Julho/2019 } \\
\text { - Projeto submetido ao Edital } \\
\text { de Chamada Pública n }{ }^{\circ} \text { 14/2018 } \\
\text { Bahia Produtiva }\end{array}$ & $\begin{array}{c}\text { Elaboração } \\
\text { de Projetos } \\
\text { Socioambientais } \\
\text { para investimentos }\end{array}$ & $\begin{array}{c}\text { - Indicadores, } \\
\text { Resultados, Planos de } \\
\text { ação }\end{array}$ \\
\hline
\end{tabular}

Fonte: Elaborado pelas autoras (2019).

Observa-se que, em cada etapa desenvolvida, foi necessário replanejar as etapas seguintes, a partir dos diálogos desenvolvidos e vivências compartilhadas, em que se evidenciavam as necessidades e os anseios da comunidade. 
A partir das experiências verificadas no Projeto Licuri IFBA em Caldeirão Grande-BA e das ações de pesquisa e extensão vivenciadas a partir do Projeto de Extensão das Oficinas de Qualificação Profissional na Comunidade de Barraquinha, foi elaborado um plano de metas e ações, demonstrado no Quadro 2, que poderia orientar as próximas etapas de reaplicação de TS no local e, por conseguinte, contribuir com o desenvolvimento socioeconômico da comunidade. As etapas do plano de ações foram estruturadas com base nas propostas dos editais do IFBA e do Bahia Produtiva, metodologicamente inspirados no trabalho de Carvalho (2006), intitulado 'Metodologia para elaboração de projetos sociais participativos', uma vez que, para a citada autora, os projetos sociais devem contemplar ações no sentido de privilegiar a participação da comunidade desde a sua concepção, ao passo em que se deve priorizar também a qualidade no planejamento de projeto. 
Quadro 2 - Plano de Metas e Ações para a comunidade de Barraquinha

\begin{tabular}{|c|c|c|}
\hline METAS & AÇÕES & $\begin{array}{l}\text { RESULTADOS } \\
\text { ESPERADOS }\end{array}$ \\
\hline $\begin{array}{l}\text { Conhecer } \\
\text { previamente a } \\
\text { realidade local. }\end{array}$ & $\begin{array}{l}\text { - Realização de Diagnóstico Participativo - é } \\
\text { possível ampliar o Diagnóstico inicial a cada } \\
\text { etapa do projeto; } \\
\text { - Definir a área com a qual se deseja trabalhar; } \\
\text { - Levantar dados e informações preliminares; } \\
\text { - Definir público possivelmente atendido (direta } \\
\text { ou indiretamente); } \\
\text { - Identificar lideranças, instituições e pessoas- } \\
\text { chave na comunidade; } \\
\text { - Manter registros descritivos e reflexivos em } \\
\text { Diário de Campo; } \\
\text { - Socializar os dados obtidos no processo; } \\
\text { - Convidar para reuniões coletivas entre os } \\
\text { atores e com grupos afins, como a que foi feita } \\
\text { com a participação do comunitário de Caldeirão } \\
\text { Grande-BA; } \\
\text { - Estimular o processo de formação da } \\
\text { consciência crítica e autocrítica da comunidade; } \\
\text { - Discutir coletivamente os problemas que } \\
\text { incomodam a comunidade, } \\
\text { - Identificar potencialidades locais e qualidades } \\
\text { do público atendido que poderão contribuir para o } \\
\text { sucesso das iniciativas. }\end{array}$ & $\begin{array}{l}\text { - Verificar a viabilidade } \\
\text { favorável ao processo de } \\
\text { reaplicação das TS. } \\
\text { - Definir quais TS } \\
\text { podem ser reaplicadas. } \\
\text { - Superar coletivamente } \\
\text { as adversidades, traçando } \\
\text { estratégias para buscar } \\
\text { coletivamente resultados } \\
\text { favoráveis. }\end{array}$ \\
\hline $\begin{array}{l}\text { Prospectar } \\
\text { oportunidades: } \\
\text { buscar parcerias e } \\
\text { apoio da sociedade }\end{array}$ & $\begin{array}{l}\text { - Identificar instituições locais/regionais que } \\
\text { podem vir a se tornar parceiras da iniciativa; } \\
\text { - Conversar com representantes das instituições } \\
\text { identificadas; } \\
\text { - Convidá-los para participar das reuniões } \\
\text { coletivas; } \\
\text { - Pesquisar instituições de fomento; } \\
\text { - Pesquisar editais e chamadas públicas } \\
\text { relacionados ao que tiver sido construído } \\
\text { coletivamente em termos de problemas e soluções; } \\
\text { - Diálogos propositivos entre os agricultores } \\
\text { associados da Barraquinha e os cooperados da } \\
\text { Cooperlic, com vistas a parcerias que promovam } \\
\text { a capacitação para o cultivo e o beneficiamento do } \\
\text { licuri; } \\
\text { - Diálogos com representantes governamentais e } \\
\text { da Administração Pública. }\end{array}$ & $\begin{array}{l}\text { - Prover a demanda por } \\
\text { apoio técnico-científico } \\
\text { para o fortalecimento das } \\
\text { ações da comunidade da } \\
\text { Barraquinha; } \\
\text { - Promover acordo } \\
\text { de cooperação } \\
\text { técnica, concessão e/ } \\
\text { ou empréstimo do } \\
\text { maquinário para o } \\
\text { beneficiamento do } \\
\text { licuri; submeter projetos } \\
\text { em editais de fomento } \\
\text { e obter êxito nas } \\
\text { submissões. }\end{array}$ \\
\hline
\end{tabular}




\begin{tabular}{|c|c|c|}
\hline $\begin{array}{l}\text { Estruturação do } \\
\text { espaço físico como } \\
\text { um ambiente de } \\
\text { produção acessível } \\
\text { a todos os membros } \\
\text { da comunidade. }\end{array}$ & $\begin{array}{l}\text { - Providenciar a instalação da energia trifásica; } \\
\text { - Limpar e arrumar as máquinas da Casa de } \\
\text { Farinha, } \\
\text { - Organizar o espaço de modo a estruturar } \\
\text { diversos processos de beneficiamento. }\end{array}$ & $\begin{array}{l}\text { - Suprir a demanda } \\
\text { por espaço físico com } \\
\text { infraestrutura adequada } \\
\text { ao funcionamento de um } \\
\text { ambiente de produção } \\
\text { para o beneficiamento do } \\
\text { licuri e outras culturas, } \\
\text { como a mandioca, feijão, } \\
\text { etc. }\end{array}$ \\
\hline $\begin{array}{l}\text { Criar uma marca } \\
\text { e promover a sua } \\
\text { inserção e seu } \\
\text { fortalecimento no } \\
\text { mercado. }\end{array}$ & $\begin{array}{l}\text { - Disponibilizar apoio técnico para criação da } \\
\text { marca, } \\
\text { - Apontar produtos a serem desenvolvidos, } \\
\text { testados e comercializados. }\end{array}$ & $\begin{array}{l}\text { - Consolidar a marca e } \\
\text { uma cartela de produtos } \\
\text { de boa qualidade } \\
\text { comercializáveis. }\end{array}$ \\
\hline $\begin{array}{l}\text { Estruturar } \\
\text { coletivamente o } \\
\text { projeto, efetuando } \\
\text { tomada de decisões e } \\
\text { delimitando prazos e } \\
\text { custos. }\end{array}$ & $\begin{array}{l}\text { - Fazer o mapeamento dos recursos disponíveis } \\
\text { (humanos, financeiros, materiais e tecnológicos) } \\
\text { necessários; } \\
\text { - Definir de forma coletiva o modo de } \\
\text { organização jurídico-social do projeto, ex.: criação } \\
\text { de uma cooperativa; } \\
\text { - Fazer o mapeamento dos recursos já existentes; } \\
\text { - Construir a matriz de interdependência recursos } \\
\text { - atividades; } \\
\text { - Com base na matriz e nos prazos definidos para } \\
\text { as atividades, construir o cronograma físico- } \\
\text { financeiro do projeto. } \\
\text { Obs.: É possível que este processo se desenvolva } \\
\text { por meio da incubação social. }\end{array}$ & $\begin{array}{l}\text { - Estruturar } \\
\text { coletivamente o projeto, } \\
\text { efetuando tomada de } \\
\text { decisões e delimitando } \\
\text { prazos e custos. }\end{array}$ \\
\hline $\begin{array}{l}\text { Qualificar a } \\
\text { comunidade } \\
\text { e prestar } \\
\text { apoio técnico- } \\
\text { científico para o } \\
\text { fortalecimento } \\
\text { da associação e } \\
\text { organização das } \\
\text { práticas produtivas. }\end{array}$ & $\begin{array}{l}\text { - Realizar levantamento de demandas } \\
\text { para promover outros módulos de oficinas } \\
\text { profissionais, apoiar o desenvolvimento de } \\
\text { novos produtos e processos, testes dos produtos } \\
\text { em laboratório e outros programas a serem } \\
\text { implantados. }\end{array}$ & $\begin{array}{l}\text { - Disponibilizar } \\
\text { os resultados do } \\
\text { levantamento das } \\
\text { demandas territoriais. }\end{array}$ \\
\hline $\begin{array}{l}\text { Iniciar o processo } \\
\text { de incubação com } \\
\text { a Associação da } \\
\text { Barraquinha, em } \\
\text { parceria com o } \\
\text { IFBA, com vistas à } \\
\text { profissionalização } \\
\text { do negócio. }\end{array}$ & $\begin{array}{l}\text { - Elaborar e formatar os demais documentos } \\
\text { referentes ao modelo de negócio escolhido, } \\
\text { - Manter a interação com a comunidade } \\
\text { por meio de reuniões, visitas técnicas, } \\
\text { rotina de treinamentos e suporte técnico no } \\
\text { desenvolvimento de produtos e processos. }\end{array}$ & $\begin{array}{l}\text { Fomentar o } \\
\text { desenvolvimento, } \\
\text { a autonomia, o } \\
\text { empoderamento por } \\
\text { meio do processo de } \\
\text { incubação, articulada } \\
\text { entre os atores sociais. }\end{array}$ \\
\hline
\end{tabular}

Fonte: Elaborado pelas autoras (2019) 


\section{CONSIDERAÇÕES FINAIS}

A ampla repercussão dos bons resultados obtidos pelo Projeto Licuri IFBA em Caldeirão Grande, assim como o início das atividades de reaplicação das Tecnologias Sociais em Jequié, mostraram que é possível, na Comunidade de Barraquinha, a priori, o uso de TS, tais como a colheita do licuri diretamente na palmeira; o uso do secador solar e da máquina de quebra; a associação do cultivo do licuri com outras culturas, como a farinha de mandioca; a produção de artesanato e estratégias comerciais para agregar valor aos produtos. A posteriori, também se vislumbra a possibilidade da fabricação de bebidas, óleos, alimentos e uso medicinal.

Tais considerações foram possíveis por meio das ações preparatórias para a reaplicação de TS no local, ao longo de mais de um ano de atividades de pesquisa que envolveram a realização das oficinas profissionais; o contato contínuo com a comunidade; a prestação de apoio técnico para elaboração de projetos; as orientações sobre empreendedorismo, produção, comercialização, qualidade dos recursos hídricos. Faz-se necessário salientar que um dos principais aspectos de distinção do processo de reaplicação das Tecnologias Sociais para as formas de Transferência Tecnológica consiste na coconstrução das TS, podendo envolver comunidade, pesquisadores das ICTs e entes governamentais. Outrossim, os atores envolvidos no processo trabalham em parceria, com participação efetiva em todas as etapas de adequação e produção, sendo importante, ainda, a construção de uma rede de apoio onde estejam intrínsecos os conceitos de Economia Solidária e Cooperativismo, na criação de um capital social que promova o desenvolvimento e a fixação dos homens e das mulheres no campo com condições dignas de vida.

À guisa de considerações, também se destaca que, a partir das experiências e do aprofundamento analítico-conceitual, a reaplicação de Tecnologias Sociais promove o empoderamento da comunidade rural, mediante um processo participativo de adequação sociotécnica, associando o desenvolvimento tecnológico e o papel social. Na concretização da proposta desenvolvida houve apoio e engajamento dos moradores da Comunidade de Barraquinha/Jequié-BA durante todo o processo, o que propiciou ambientes de interação entre ICT-comunidade, a difusão do conhecimento acadêmico-científico, assim como a formação de cidadãos capazes de perceber a ciência em suas múltiplas dimensões, como agente transformadora da qualidade de vida e das relações entre os indivíduos, e também como um processo histórico e social.

\section{REFERÊNCIAS}

CARVALHO, Vanessa F. Mendonça de. Metodologia para elaboração de projetos sociais participativos. XXVI ENEGEP, Abepro, Fortaleza-CE, 9 a 11 de out de 2006. Disponível em: http://www.abepro.org.br/ biblioteca/enegep2006_TR560372_8646.pdf. Acesso em: 17 de outubro de 2019.

CHAVES, Maria do Perpétuo Socorro Rodrigues; LIRA, Talita de Melo; SILVA, Mayara Pereira da; NUNES, Rosa Maria da Silva; BARRETO, Jéssica da Silva; MEDEIROS, Vânia Lima. TECNOLOGIAS SOCIAIS: experiência do Grupo Inter-Ação para desenvolvimento de tecnologias sociais em comunidades ribeirinhas na Amazônia. Anais do VI Encontro Nacional do Anppas. 2012, Belém-PA. Disponível em: http:/www.anppas.org.br/encontro6/anais/ARQUIVOS/GT5-1348-1277-20120630111633.pdf . Acesso em 27 de julho de 2019.

DAGNINO, Renato (org.). A Tecnologia Social e seus desafios. Tecnologia Social: ferramenta para construir outra sociedade. 2. ed. rev. e ampl., Campinas, SP: Komedi, 2010. 
DAGNINO, Renato; BRANDÃO, Flávio Cruvinel; NOVAES, Henrique Tahan. Sobre o marco analítico conceitual da tecnologia social. In: LASSANCE JR. et. al. (Orgs.). Tecnologia Social: uma estratégia para o desenvolvimento. Fundação Banco do Brasil, Rio de Janeiro, 2004. p. 15-64.

DAGNINO, Renato; NOVAES, Henrique. O fetiche da tecnologia. Revista ORG \& DEMO. v. 5, n. 2 (2004). Disponível em: http://200.145.171.5/revistas/index.php/ orgdemo/article/view/411/311. Acesso em: 03 de novembro de 2017.

FREITAS, Carlos César Garcia; SEGATTO, Andrea Paula. Ciência, Tecnologia e Sociedade pelo olhar da Tecnologia Social: um estudo a partir da teoria crítica da tecnologia. Cadernos EBAPE.BR, Rio de Janeiro, v. 12, n. 2, p. 302 a 320, jun. 2014. ISSN 1679-3951. Disponível em: <http://bibliotecadigital.fgv.br/ojs/ index.php/ cadernosebape/article/view/7420>. Acesso em:19 janeiro de 2019.

INSTITUTO FEDERAL DE EDUCAÇÃO, CIÊNCIA E TECNOLOGIA DA BAHIA. Projeto Licuri. Disponível em: http://portal.ifba.edu.br/proex/acoes/projeto-licuri. Acesso em: 12 de novembro de 2017.

JESUS, Djane Santiago de; SANTOS, Carla Renata Santos dos; SANTANA, Genice de Jesus. 10868 Colhedores de licuri: a agroecologia e a Tecnologia Social como estratégias para o desenvolvimento rural sustentável no semiárido. Resumos do VII Congresso Brasileiro de Agroecologia - Fortaleza/CE - 12 a 16/12/2011. Cadernos de Agroecologia, Vol 6, No. 2, Dez 2011.

LASSANCE JR. et. al. (Orgs.). Tecnologia Social: uma estratégia para o desenvolvimento. Fundação Banco do Brasil, Rio de Janeiro, 2004.

MATARAZZO, Gustavo; BOEIRA, Sérgio Luis. Incubação de cooperativas populares: representações sociais e tensões entre racionalidades. Cad. EBAPE.BR, v. 14, $\mathrm{n}^{\mathrm{o}}$ 1, Artigo 10, Rio de Janeiro, Jan./ Mar. 2016 (FGV). Disponível em: http://bibliotecadigital.fgv.br/ojs/index.php/cadernosebape/article/ view/31514. Acesso em: 21 de maio de 2019.

MELLO, Ricardo de F.; MELLO, Ruth E. S. de. Tecnologia Social e economia solidária e as possibilidades de inserção soberana na economia. VII ENEDS - Teófilo Otoni, MG, Brasil, 23 e 24 de Setembro de 2010. Disponível em: http://www.genesis.puc-rio.br/media/biblioteca/Tecnologia_Social_e_economia_s.pdf . Acesso em: 03 de julho de 2019.

RODRIGUES, Ivete; BARBIERI, José Carlos. A emergência da tecnologia social: revisitando o movimento da tecnologia apropriada como estratégia de desenvolvimento sustentável. In Revista de Administração Pública, Rio de Janeiro-RJ, nov-dez/2008. Disponível em: http://www.scielo.br/pdf/rap/v42n6/03.pdf . Acesso em: 03 de julho de 2019.

SANTOS, Carla Renata Santos dos; JESUS, Djane Santiago de (orientação); CYPRIANO, Carlos Alex de Cantuári. (coorientação). Conectando saberes e práticas plurais: um olhar sob a ótica da tecnologia social e o licuri. Repositório SIBI/UFBA/Faculdade de Educação - Biblioteca Anísio Teixeira, Salvador: 2017a. Disponível em: http://repositorio.ufba.br/ri/handle/ri/22475. Acesso em: 02 de novembro de 2018.

SANTOS, Carla Renata Santos dos; CYPRIANO, Carlos Alex de Cantuária; JESUS, Djane Santiago de. Tecnologias para o Desenvolvimento Inclusivo Sustentável: da Exclusão ao Empoderamento (p 747759). In: Incubadora Tecnológica de Cooperativas Populares - ITCP-USP “Autogestão, cooperativismo e economia social e solidaria: experiencias latino americanas: memórias do XIII Seminário Internacional Procoas AUGM", ITCP-USP, São Paulo: 2017b. Disponível em: http:/grupomontevideo.org/ndca/ caprocesoscooperativos/wp-content/uploads/ 2018/02/Autogest\%C3\%A3o-cooperativismo-e-economiasocial-e-solid $\% \mathrm{C} 3 \% \mathrm{~A} 1 \mathrm{ria}-\mathrm{experi} \% \mathrm{C} 3 \% \mathrm{AAncias}$-latino-americanas-mem\%C3\%B3rias-do-XIIISemin\%C3\%A1rio-Internacional-Procoas.pdf . Acesso em: 10 de maio de 2019.

SCHWAB, Diego; FREITAS, Carlos Cesar Garcia. Tecnologia Social: implicações e desafios da implantação. R. Tecnol. Soc., Curitiba, v. 12, n. 26, p. 42-60, set./dez. 2016 (UTFPR). Disponível em: https://periodicos.utfpr.edu.br/rts/article/viewFile/3794/pdf. Acesso em: 10 de novembro de 2017. 